\section{Dental market debated at DentalForum event}

The state of the dental market was discussed at the DentalForum UK 2018 conference held in Marbella on 21 and 22 June 2018 with Dental Elite hosting an Ignite session on how dental groups are evolving and what will be the best route to market moving forward.

Presented by Co-Founder Luke Moore and the Director of Recruitment Services, Luke Arnold, the insightful session explored both the current difficulties surrounding recruitment, and how this might impair the growth of dental businesses in the future.

Moore said: 'It is no secret that practices are finding it increasingly more difficult to recruit. What we're interested in is how this might have an impact on goodwill values, and in turn a principal's ability to grow and sell their dental practice.'

Similar concerns were raised by a number of other delegates over the course of the two-day event, with recruitment and business growth discussed at length by a range of professionals.

'Above all else, this shows that everyone has been affected by the current state of the market not just independents', added Moore. 'If anything, larger dental groups and corporates are feeling the affect more than smaller groups and individual practices.'

More information on Dental Elite is available at www.dentalelite.co.uk or by email at info@dentalelite.co.uk or by calling 01788545900.

\title{
Good choice for overdentures
}

The Kerator Overdenture system by Trycare is a popular choice amongst clinicians as it provides improved system componentry at the point of ordering and can be placed clinically across both implant abutments and components and into roots of endodontically treated teeth.

Kerator abutments are compatible with all implant systems including Adin, Nobel Biocare, Starumann, 3I, Astra, Straumann, Ankylos, Biohorizon, Biolok, Bicon, Camlog, Endopore, Frialit-2 \& Xive, Lifecore, Zimmer (Calcitek, Paragon, Swissplus), Uniti, Pitt-Easy, Osstem, Dentium, Dio, Dentis, Megagen, Cowell Medi, Warantec and many more.

Kerator components and instruments are also available individually.

For root-retained overdentures, there are two types:

- The post type used in direct technique and these are available as straight, 10 degree and 20-degree angled females. The female part is made of titanium alloy and is coated with titanium nitride

- The cast type has a pattern that is incorporated into wax pattern for post coping. The Kerator Root Kit includes 4 attachments (male \& female), 3 kinds of burs, initial drill, main pilot drill, countersink diamond bur.
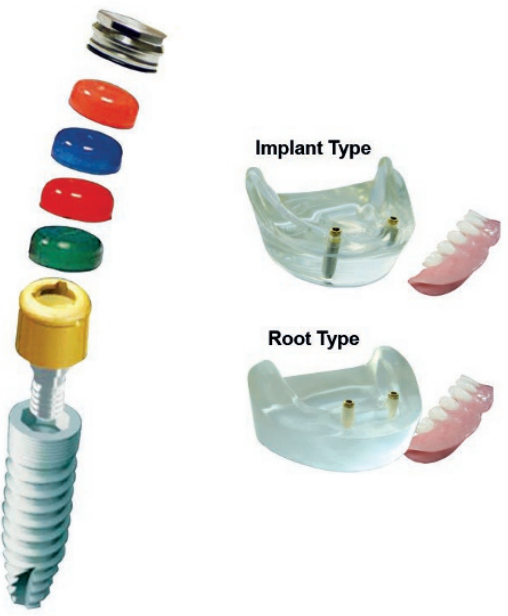

Trycare says it is committed to bringing customers the best possible solutions clinically across many treatment pathways, while ensuring value for money.

The company says the key benefits are:

- Plastic carrier for the abutment

- The lowest vertical height production

- Dual retention

- Resilient KERATOR attachment

- $15^{\circ}$ angled abutment

- Retentive property - increasing coherence with denture resin.

More information is available at www. trycare.co.uk/kerator or by calling the company on 01274885544 to request a visit from a local Trycare area sales manager.

\section{More growth for dental corporate}

A further nine dental practices have now joined Dental Partners, one of the UK's fastest growing dental corporates.

Dentapol, a group of six predominantly NHS practices based in Dorset which have been built up since 2006 by the Drozdziel family, now comes under Dental Partners' wing.

Spread across Dorset in

Bournemouth, Dorchester, Ferndown, Weymouth, Sturminster Newton and Christchurch, their acquisition boosts Dental Partners' reach in the South.

Further north, three well-established, community-based NHS dental practices have also joined the Dental Partners network - Johnson and Whitehouse in Blacon, Chester and The Newtown Dental Centre and Broadway Dental Care both in St Helens, Merseyside.

Neil Lloyd, Chief Executive Officer at Dental Partners said of the latest acquisitions: 'Our approach is to only take on high-quality, well-run practices with good local reputations.

'We always want to maintain the brand and reputation that our practices have built up over years of working in their communities as well as the staff culture. I visit every practice we consider for acquisition and the measure for me is 'Would I like to work here?' The answer has to be yes for us to go ahead.

'Acquiring practices and groups is an exciting development for Dental Partners, as we continue to forge a new and innovative approach to corporate dentistry. We look forward to the challenges ahead and to helping make a positive difference to the team and patients at all our practices.'

The company said it was now providing full support to the new practices so that they could be 'the best place to work' and deliver the best dental care to their patients.

They did this by giving them a great environment to work in and assistance with equipment, practice marketing and compliance, while leaving the clinical decisions down to the practices.

More information is available at www. dentalpartners.co.uk or by emailing contact@dentalpartners.co.uk. 